\title{
AN EXPERIMENTAL STUDY ON THE BOLTED JOINT CONNECTIONS IN GFRE [0/90 $]_{2 S}$ LAMINATES
}

\author{
A. I. Selmy, U. A. Khashaba and T. A. Sebaey \\ Mechanical Design and Production Engineering Department, Faculty of Engineering \\ Zagazig University, P.O. Box 44519, Zagazig, Egypt. \\ Corresponding: sepaey@hotmail.com
}

\begin{abstract}
Bolts provide the primary means of connecting composite parts in the construction of aircrafts and aerospace vehicles. The objective of the present study is to determine the effect of bolt / hole clearance and the cut-off angle on the failure load and mode of laminated Glass Fiber Reinforced Epoxy laminates (GFRE) with 0.4 fiber volume fraction. Five clearance values were used. The results showed that the specimen Failure Load decreased by increasing the clearance value and the failure mode did not affected. Four cut of angles were tested. The results showed that the failure load decreased as the cut-off angle increased up to $30^{\circ}$ and then increased.

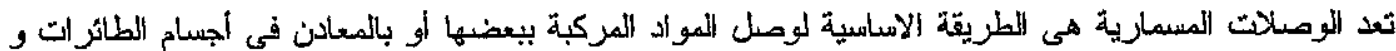

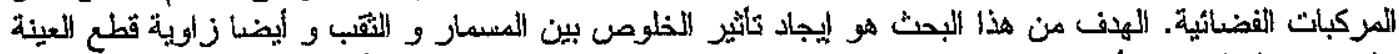

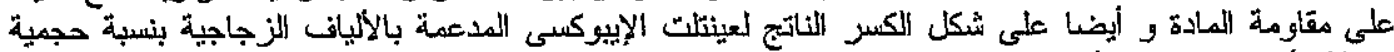

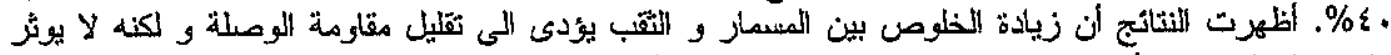

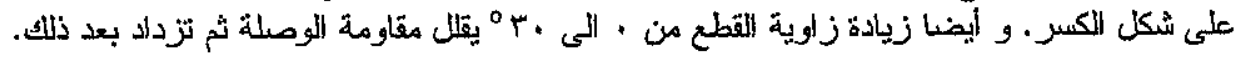

Keywords: Experimental, Bolted Joint, Composite, Bolt / Hole Clearance, Cut-off angle, GFRE.

\section{INTRODUCTION}

Bolted joints are widely used in composite structures of aircraft to fasten components together. They offer easy inspection, low cost, easy of manufacturing, and reliability compared with bonded joints, and furthermore, bolted joints structural parts can be easily removed for maintenance replacement. To all that reasons the bolted joints have an important value.

The main disadvantage of bolted joints is the formation of high stress concentration zones at the location of bolt holes, which might lead to a premature failure of the joint [1]. In addition to the stress concentration around the bolt hole, the drilling process, to create the bolt hole, breaks reinforcing glass fibers, and causes; (1) pealing of the higher plies at the entry of the hole, (2) fiber wrenching and resin degradation on the wall of the hole, and (3) delamination of the least plies in the laminate. Since these damages can initiate cracks [2-4].

It has been observed experimentally that mechanically fasted joints fails under three basic mechanisms: net tension, shear out, and bearing failure. Typical damage caused by each mechanism is shown in Fig.1. There is another type of failure mode called cleavage failure, which takes place in laminates having only $0^{\circ}$ fibers [5].

In a typical manufacturing environment, the diameters of the fasteners and holes will follow a statistical distribution within allowable limits and fits, leading to a range of possible bolt-hole clearances [6]. DiNicola and Fantle investigated the effects of clearance on pin-loaded quasi-isotropic carbon fiber epoxy laminates. Specimens with bolthole clearances of 0 (neat fit), 76, 152 and $276 \mathrm{~mm}$ for nominal hole diameters of 3.18 and $6.35 \mathrm{~mm}$ were compared and the bearing strength determined as the stress at $4 \%$ deformation of the hole diameter and the stress at the ultimate bearing load. The bearing strength at $4 \%$ hole deformation was found to decrease significantly with the increase in clearance but the ultimate bearing strength exhibited limited dependence on the clearance[7]. A similar conclusion was observed by Lawlor et al [8].

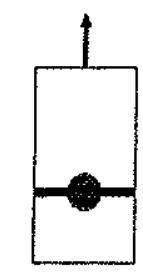

Net tension

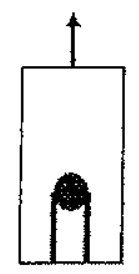

Shear out

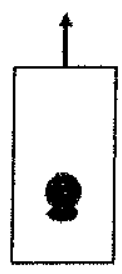

Bearing

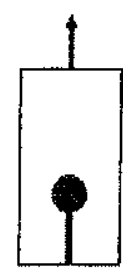

Cleavage
Fig. 1 Failure modes of bolted Laminates

Khashaba [9] investigates the effect of cut-off angle on the shear strength of $[0 / 90]_{2 S}$ GFRE laminates. The results showed that the maximum in-plane shear strength is found for specimens with $45^{\circ}$ and $60^{\circ}$ offaxis angles, i.e. for $[45 /-45]_{2 \mathrm{~S}}$ and $[60 /-30]_{2 \mathrm{~S}}$ 
specimens respectively. On the other hand specimens with $0^{\circ}$ and $90^{\circ}$ off-axis angles have the minimum inplane shear strength.

Icten et al. [10] presented a comparative experimental and numerical study between $\left[(0 / 90)_{3}\right]_{\mathrm{s}}$ and $\left[( \pm 45)_{3}\right]_{S}$ stacking sequences for GFRE. They found that the $\left[( \pm 45)_{3}\right]_{s}$ specimens failed as bearing failure mode while the $\left[(0 / 90)_{3}\right]_{\mathrm{S}}$ failed as shear out failure mode with notation of slight evidence of bearing damage around the hole. In terms of failure load, the failure load of cross-ply laminates is greater than it for angle ply ones.

The scope of the present study is to determine the effect of clearance and cut- off angles upon the failure load and failure mode of $[0 / 90]_{2 S}$ GFRE laminates. Two criteria are used to define the failure load. The first definition of the failure load is the load corresponding to the ultimate load in the loaddisplacement curve, ASTM D5961/D5691 M.01. The second definition of the failure load is the load corresponding to the first beak in the loaddisplacement curve, [11]. The used fastener is DIN 931 bolt. All tests are performed according the ASTM D5961 / D5691 M.01.

\section{EXPERIMENTAL WORK}

\subsection{Specimen Manufacturing and Preparation}

The material of the specimen is Glass fibers and Epoxy matrix. The glass fiber is E-roving glass fiber linear density $=2100 \mathrm{~g} / \mathrm{Km}$. The matrix is Araldite PY 1092 (100 part by weight) with Hardener HY 1092 (50 part by weight). The manufacturing hand lay-up technique was summarized by Khashaba, Ref [9]. The designed dimensions of the test specimens were achieved using milling machine within a tolerance of $\pm 0.05 \mathrm{~mm}$. The cutting parameters were selected to prevent the delanination of the specimen edges; feed $=0.07 \mathrm{~mm} /$ tooth and speed $=250 \mathrm{rpm}$, [5]. The dimensions of the laminated specimen were $3.2^{ \pm 0.1} \mathrm{~mm}$ thickness, $135^{ \pm 0.1} \mathrm{~mm}$ length and $36^{ \pm 0.1}$ $\mathrm{mm}$ width. The fiber volume fraction was determined experimentally by physical removing the matrix using the ignition technique according to ASTM D3171-99. The fiber volume fraction is the average value of the three specimens. The volume fraction of the unidirectional and cross-ply laminates is $40^{ \pm 0.5} \%$.

The hole was machined using the lathe machine. The specimen was clamped into a four-jaw chuck with a wood back-up plate of the same dimensions to overcome the delamination on the back surface of specimen. A hole of $3 \mathrm{~mm}$ diameter was drilled first. Then, by the same setup, the tool was fed transversely by a very small distance. The hole diameter was measured after each feed step using a micrometer of $0.01 \mathrm{~mm}$ resolution. The sequence was repeated until the desirable hole diameter (nominal bolt diameter + clearance). The nominal bolt diameter is $5.88 \mathrm{~mm}$.

\subsection{Bolted Joint Test}

The failure of bolted joints was determined experimentally according to ASTM D5961, [12]. Standard specimens were chosen to ensure that the failure would occur in bearing mode, not in net tension or shear-out. The bolted joint test fixure, Fig. 2, were manufactured from stainless steel according to ASTM D5961/D5961M.

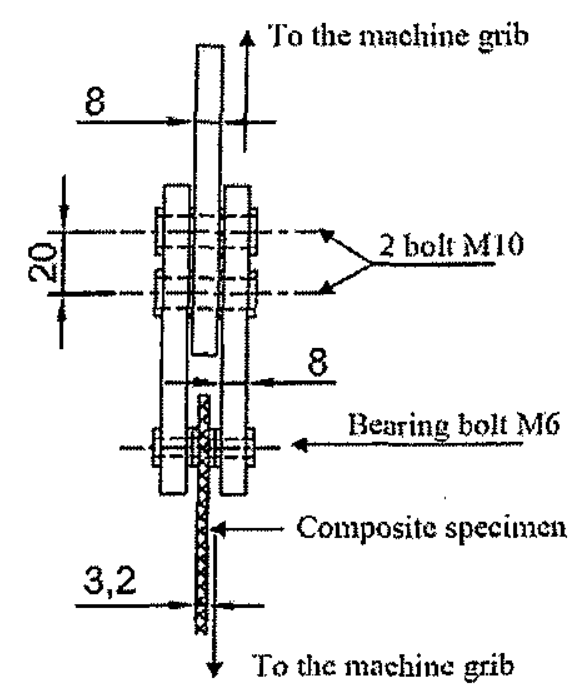

Fig. 2 Bolted joint fixture.

The present study investigates the effect of bolt / hole clearence on bolted joint failure characterrstics. The clearances, $\mathrm{C}^{ \pm 10} \mu \mathrm{m}$, under examination are shown in Table 1; they are coded C1-C5 for reference. Clearances $\mathrm{C} 1$ and $\mathrm{C} 2$ are within current aerospace tolerances $(75 \mu \mathrm{m})$, while $\mathrm{C3}$ to $\mathrm{C5}$ are slightly outside. The latter three clearance values are thus of interest in examining the possible effects of out-of tolerance aerospace holes (or fasteners), and also in non-aerospace applications [13].

Table 1. Clearance values

\begin{tabular}{|l|c|c|c|c|c|}
\hline Code & C1 & C2 & C3 & C4 & C5 \\
\hline $\mathrm{C}, \mu \mathrm{m}$ & 0.0 & 50 & 100 & 200 & 300 \\
\hline
\end{tabular}

The present study also investigates the effect of cutoff axis upon the failure load and failure mode of the bolted joint specimen. Three cut-off axis angles $\left(15^{\circ}\right.$, $30^{\circ}$, and $45^{\circ}$ ) are considered. The three off-axis angles produce three different stacking sequences $\left([15 /-75]_{2 S},[30 /-60]_{2 s}\right.$, and $\left.[45 /-45]_{2 s}\right]$, respectively, in addition to the basic stacking sequence, $[0 / 90]_{2 s}$.

The bolted joint tests were performed using a 100 ton UH-F1000 KNI, SHIMADZU universal testing machine at the Central Metallurgical Research and Development Institute (CMRDI). The machine provides hydraulic grips to ensure that there is no sliding between bolted joint fixture and the grip surface. 


\section{RESULTS AND DISCUSSION}

\subsection{Cross-Ply Laminates}

Fig. 3 shows the load-displacement diagram of bolted joint in $[0 / 90]_{2 S}$ GFRE specimen without bolt/hole clearance. The diagram was accompanied with some photographs that illustrate the failure sequence of the specimen. The initial portion in the loaddisplacement curve (up to $0.5 \mathrm{kN}$ ) exhibit a nonlinear behavior followed by a linear manner up to 3.6 $\mathrm{kN}$, then a nonlinear behavior was appeared again. The first nonlinear portion was due to the clearance in the machine joints and the roughness (irregularities) of both the drilled hole and the bolt. The full contact of the bolt/hole was carried after 0.5 $\mathrm{kN}$. The test were stopped at $1.8 \mathrm{kN}$ and visually examined, Fig.3. The specimen exhibits delamination-free at this load. On the other hand matrix damage and fiber splaying was observed at $2.5 \mathrm{kN}$, Fig.3. The second nonlinear behavior (after $3.6 \mathrm{kN}$ ) was due to bearing failure associated with shear out initiation of $0^{\circ}$ layers. The bearing area and the shear out of $0^{\circ}$ layers were clearly observed at $4.75 \mathrm{kN}$. The net-tension failure mode of $90^{\circ}$ layer was observed at the maximum load, $5.35 \mathrm{kN}$. All the test specimens were failed in the same manner (bearing failure associated with shear-out, followed by net tension mode).

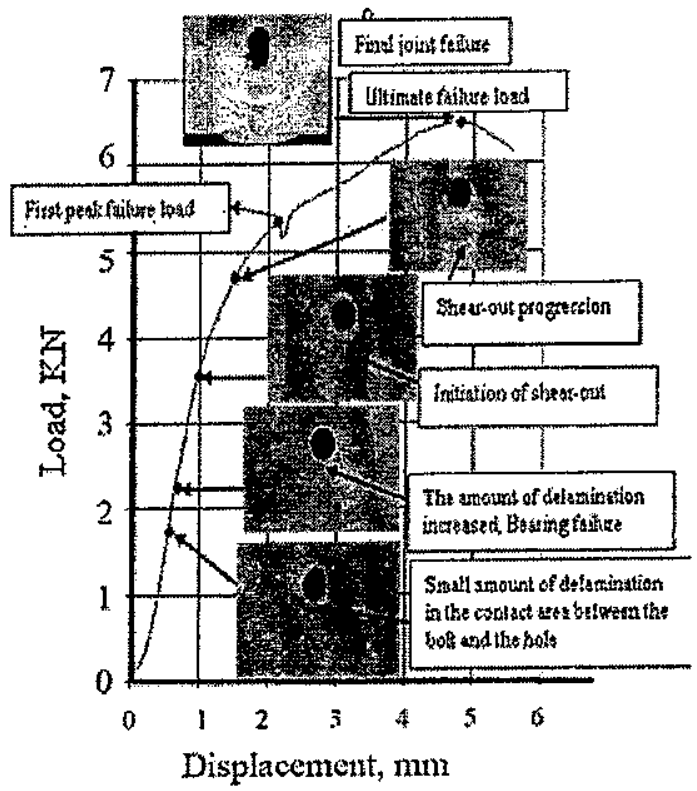

Fig. 3 Load-displacement curve for boited joint in $[0 / 90]_{2 S}$ GFRE specimen without bolt/hole clearance

Fig. 4 shows the Load-displacement curves for bolted joint in $[0 / 90]_{2 s}$ GFRE specimens with different boit/hole clearance level. The figure was accompanied with photographs of the fractured specimen. Five test specimens were tested for each clearance value. The variation of bolt/hole clearance from 0 to $300 \mu \mathrm{m}$ has insignificant effect on the qualitative behavior of the load-displacement diagrams, Fig. 4.
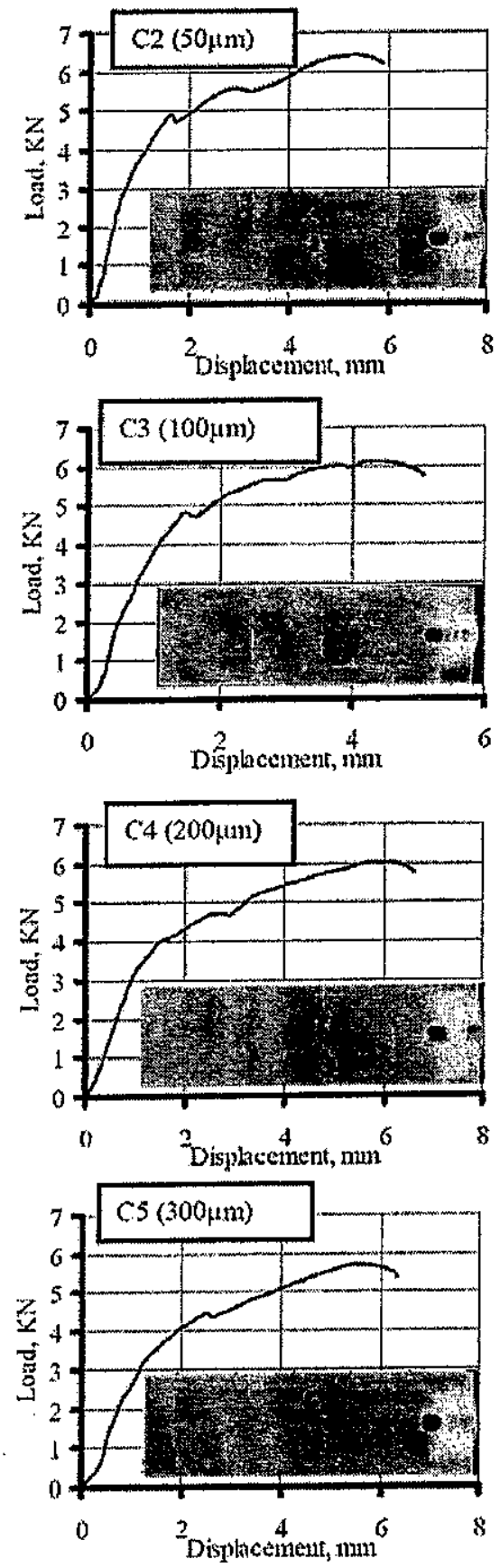

Fig. 4 Load-displacement curves for $[0 / 90]_{2 s}$ bolted joint specimens at different clearance levels

In contrast the variation of bolt/hole clearance has insignificant quantitative variation on the ultimate failure load but it has a significant effect on the first peak, Table 2. Increasing the bolthole clearance from zero to $50 \mu \mathrm{m}$ decreases the first peak and the ultimate failure loads by $7.4 \%$ and $3.5 \%$, respectively. Also, increasing the bolt/hole clearance from zero to $300 \mu \mathrm{m}$ decreases the first peak and the ultimate failure loads by $16.5 \%$ and $7.75 \%$, respectively. 
Table 2. Clearance vs. failure loads

\begin{tabular}{|c|c|c|}
\hline Code & First peak load KN & Ultimate load KN \\
\hline C1 & 5.38 & 6.394 \\
\hline C2 & 4.98 & 6.167 \\
\hline C3 & 4.88 & 6.136 \\
\hline C4 & 4.79 & 6.12 \\
\hline C5 & 4.49 & 5.86 \\
\hline
\end{tabular}

\subsection{Angle-Ply Laminates}

Fig. 5 shows the load-displacement curves for the prescribed stacking sequence at zero clearance. The values of the first peak and the ultimate loads of the bolted joints with stacking sequences are presented in Table 3.

Table 3 Stacking sequence and the corresponding failure loads

\begin{tabular}{|c|c|c|}
\hline $\begin{array}{c}\text { Stacking } \\
\text { sequence }\end{array}$ & $\begin{array}{c}\text { First peak load } \\
\mathrm{KN}\end{array}$ & $\begin{array}{c}\text { Ultimate load } \\
\mathrm{KN}\end{array}$ \\
\hline$[0 / 90]_{2 \mathrm{~S}}$ & 5.38 & 6.394 \\
\hline$[15 /-75]_{2 S}$ & 5.13 & 5.811 \\
\hline$[30 /-60]_{2 S}$ & 5.06 & 5.423 \\
\hline$[45 /-45]_{2 S}$ & 5.41 & 5.39 \\
\hline
\end{tabular}

The results indicate that the bolted joint in cross-ply laminate, $[0 / 90]_{2 s}$, has the maximum ultimate load. On the other hand the maximum first peak failure load was recorded for the bolted joint in specimens with $[45 /-45]_{2 s}$ stacking sequence. This result was due to the fact that specimens with $[45 /-45]_{2 \mathrm{~s}}$ stacking sequence have the highest value of in-plane shear strength [9] that calculated based on the maximum load just prior to the nonlinear behavior of load-displacement diagram. The values of failure loads decreased as the cut-off angle increased from 0 to $30^{\circ}$. The minimum value was observed for $[30 /-$ $60]_{2 s}$ stacking sequence.

Fig. 6 shows the failure mode for laminates with $[15 /-75]_{2 S},[30 /-60]_{2 s}$, and $[45 /-45]_{2 s}$. The failure mode of specimens with [15/-75 $]_{2 \mathrm{~S}}$ stacking sequence is a combination between the bearing and the shearout at $15^{\circ}$. Net-tension was observed, at $75^{\circ}$, in three specimens as the load further increased. Specimens with $[30 /-60]_{2 S}$, failed as a combination between bearing and shear-out at an angle of $30^{\circ}$. Pure bearing failure mode was observed for specimens with $[45 /-45]_{2 s}$ stacking sequence. In other words, the tendency of laminate with $[45 /-45]_{2 S}$ to fail in shear mode is poor [9].

Although the dimensions of all specimens are selected to obtain bearing failure mode, ASTM D 5961/D 5961M-01 [12], the experimental observation shows a different failure mode at different stacking sequences. Similar observations were reported by Potec et al. [14] and Icten et al. [10] for Eglass/epoxy laminates with $\left[(0 / 90)_{n}\right]_{s}$. They concluded that the direct application of the ASTM geometrical specifications is not suitable for the selected material. So, the failure mode is a function of stacking sequence.
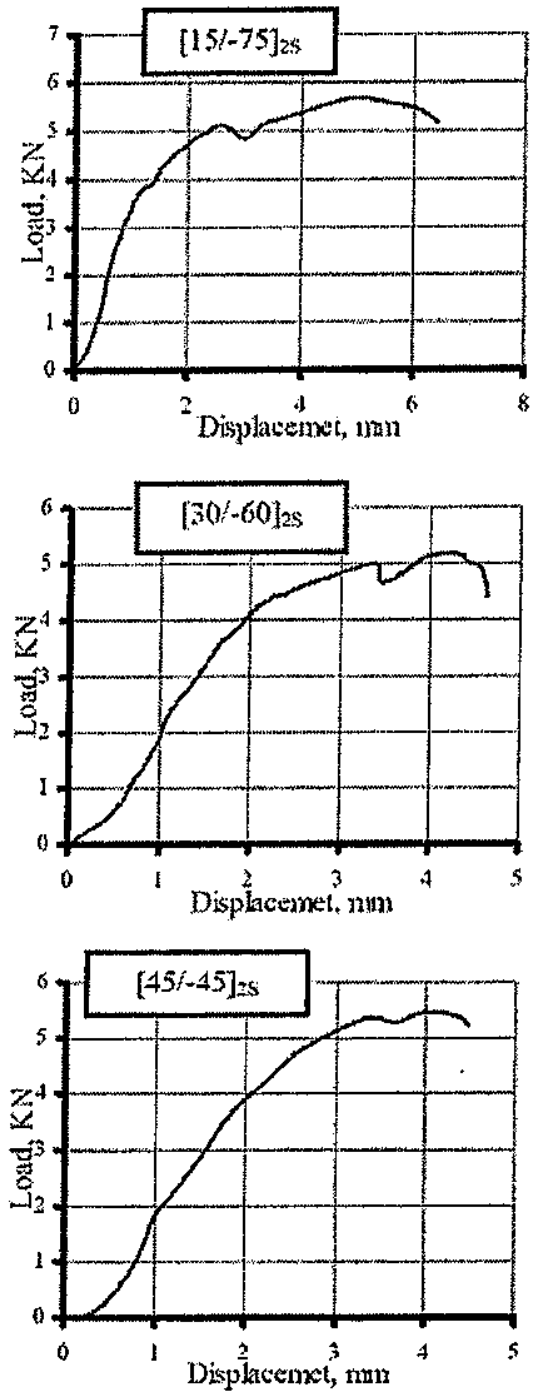

Fig. 5 Load-displacement curves for $[0 / 90]_{2 S}$ cut at $15^{\circ}, 30^{\circ}$ and $45^{\circ}$ cut-off angle

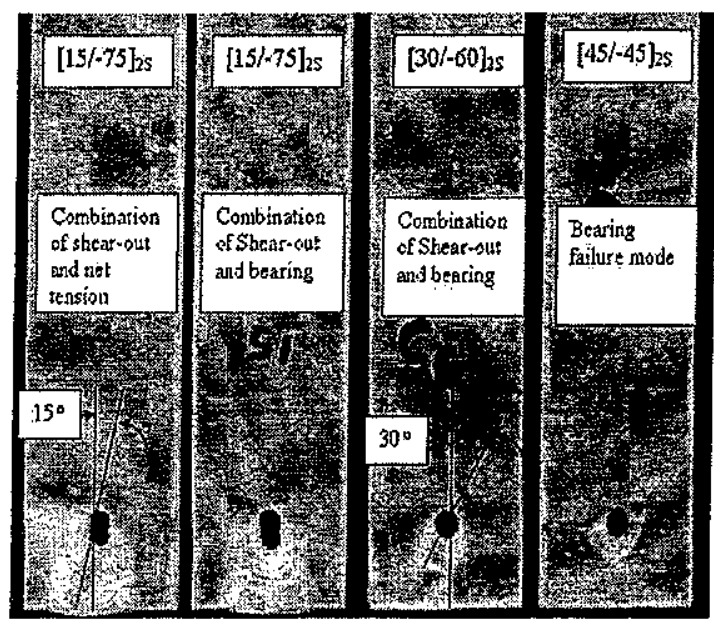

Fig. 6 Failure modes for different stacking sequence. 


\section{CONCLUSIONS}

In this work an experimental study was implemented to find the effect of geometric parameter (clearance) and material parameter (stacking sequence) on the failure characteristics (failure mode and failure mode) of GFRE laminated mechanically fastened joints. Two parameters were measured to determine the failure response; first beak and the ultimate failure loads. The results obtained lead to the following conclusions;

- The ultimate failure load slightly decreased as increasing the bolt / hole clearance within the range from zero to $300 \mu \mathrm{m}$ by $7.75 \%$. The effect of clearance on the first beak failure load is higher than it of ultimate one, $18.5 \%$.

- The failure sequence of specimen of $[0 / 90]_{2 S}$ was Bearing failure at $2.5 \mathrm{KN}$, shear-out of $0^{\circ}$ layers at $3.6 \mathrm{KN}$ then net-tension of $90^{\circ}$ layers just before final fracture of specimen

- There is no noticeable effect of clearance on the failure mode of specimen of $[0 / 90]_{2 s}$. On the other hand, the stacking sequence has a great effect on the failure mode. The specimens of $[45 /-45]_{2 S}\left(45^{\circ}\right.$ cut-off angle) stacking sequence gave the most desirable failure mode (pure bearing failure mode). The other stacking sequences gave a combination of bearing, shear-out and net-tension failure mode.

- The ultimate and the first beak failure loads decreased as the cut-off angle increased from $0^{\circ}$ to $30^{\circ}$ the decrease of the failure load was due to the decrease of the tensile strength of material under consideration as the cut-off angle increased, [9].

- The specimens with $45^{\circ}$ cut-off angles gave a higher failure load than that of $15^{\circ}$ and $30^{\circ}$. The failure load was due to its higher ability to carry shear load than other stacking sequence specimens.

\section{REFERENCES}

[1] Kradinov, V., Madenci, E. and Ambur, D.R., "Combined in-plane and through-the-thickness analysis for Failure prediction of bolted composite joints", Composite Structures, Vol. 77, PP. 127-147, (2007).

[2] Matsuzaki, R., Shibata, M. and Todoroki, A., "Improving performance of GFRP/aluminum single lap joints using bolted/co-cured hybrid method", Composites Part A: Applied science and Manufacturing, Vol. 39 PP. 154-163, (2008).
[3] Khashaba, U.A., Seif, M.A. and Elhamid, M.A., "Drilling analysis of chopped composites", Composites Part A: Applied science and Manufacturing, Vol. 38, PP. 61-70, (2007).

[4] Lin, H.J. and Tsai, C.C., "Failure analysis of bolted connections of composites with drilled and moulded-in hole", Composite Structures, Vol. 30, PP. 159-168, (1995).

[5] Mazumdar, S.K., "Composites manufacturing; materials, product and process engineering", CRC Press, LLC, (2002).

[6] McCarthy, M.A., McCarthy, C.T. and Padhi, G.S., "A simple method for determining the effects of bolt-hole clearance on load distribution in single-column multi-bolt composite joints", Composite Structures, Vol. 73, PP. 78-87, (2006).

[7] Kelly, G. and Hallstrom, S., "Bearing strength of carbon fiber/epoxy laminates: effects of bolthole clearance", Composites Part B: Engineering, Vol. 35, PP. 331-343, (2004).

[8] Lawlor, P.V., McCarthy, M.A. and Stanley, W.F., "An experimental study of bolt-hole clearance effects in double-lap multi-bolt composite joints", Composite Structures, Vol. 71, PP. 176-190, (2005).

[9] Khashaba, U.A., "In-plane shear properties of cross-ply laminate with different off-axis angles", Composite Structures, vol. 65, PP. 167177, (2004).

[10] Icten, B.M., Okutan, B. and Karakuzu, R., "Failure strength of woven glass fiber- epoxy composites pin jointed", Composite Materials, Vol. 37, PP. 1337-1350, (2003).

[11] Lin, H.J. and Tsai, C.C., "Failure analysis of bolted connections of composites with drilled and moulded-in hole", Composite Structures, Vol. 30, PP. 159-168, (1995).

[12] "Standard test method for bearing response of polymer matrix composite laminate", ASTM D5961 /D5691 M.01, American Society of Testing

[13] McCarthy, C.T. and McCarthy, M.A., "Threedimensional finite element analysis of singlebolt, single-lap composite bolted joints: part Imodel development and validation", Composite Structures, Vol. 71, PP. 140-158, (2005).

[14] Postec, M., Deletombe, E., Delsart, D. and Coutellier, D., "Study of the influence of the number of inter-ply interfaces on the bearing rupture of riveted composite assemblies", Composite Structures, Vol. 84, PP. 99-113, (2008). 